2. Chandler JR, Goulding R, Moscowitz L et al (1984) : Nasopharyngeal angiofibromas : Staging and Management. Anals of Otology Rhinology Laryngology ; 93: 323-320.

3. Cummings BJ, Blend R, Keane T et al. (1984) : Primary radiation therapy for juvenile nasopharyngeal angiofibroma. Laryngoscoe ; 94: 1599-605.

4. Fisch U (1983): The infratemporal fossa approach for nasopharyngeal tumors. Laryngoscope, 93: 36-44.

5. Geopfert H, Cangir A, Lee Y(1985) : Chemotherapy for aggressive juvenile nasopharyngeal angiofibroma. Archives of Otolaryngology and Head Neck Surgery ; 111: 285-289.

6. Jafek BW, Krekorian EA, Kirsch WM, Wood RP (1979) : Juvenile nasopharyngeal angiofibroma : Management of intracranial extension. Otolaryngology, $2: 119-28$.

7. Jafek BW, Nahum AM, Butler RM et al (1973) : Surgical treatment of Juveline Nasopharyngeal Angiofibroma. Laryngoscope ; 83: 707-720.

8. Jacobsson M, Petruson B, Svendsen P et al (1988) : Juvenile naso-pharyngeal angiofibroma : A report of 18 cases. Acta Otolaryngologica ; 105: 132-139.
9. Mickey B, Close LG, Schaefer SD, Samson D (1988) : A combined frontotemporal and lateral infratemporal fossa approach to the skull base. Journal of Neurosurgery ; 68: 678-683.

10. Sekhar LN, Moller AR, (1986) : Operative management of tumors involving the cavernous sinus. Journal of Neurosurgery 64: 879-889.

11. Ward PH (1983) : The evolving management of juvenlie nasopharyngeal angiofibroma. Journal of Laryngology Otology; Suppl $8:$ pp 103-104.

\section{Address for correspondence :}

Dr. Dinaz Namdarian

Lecturer in Department of ENT

T. N. Medical College and

B. Y. L. Nair Ch. Hospital

Dr. A. L. Nair Road

Mumbai 400 008, India.

\title{
UNUSUAL FOREIGN BODY IN THE TRACHEA
}

\author{
A. M. Shivakumar', Ashok S. Naik ${ }^{2}$, Prashanth \\ K. $\mathbf{B}^{3}$, Suman \\ S. Yeli ${ }^{4}$, Yogesh

ABSTRACT: A great variety of foreign bodies in the tracheobronchial tree have been reported, but
presence of fractured tracheostomy tube as foreign body is rare'. Usually fractured pieces of outer
tube are found in the bronchus or trachea near the carina, but occurence of inner tube in the upper
part of the trachea is rare? and one such case is presented here.

B. $S^{5}$

Key words : Trachea, Foreign body, Tracheostomy tube

\section{CASE REPORT}

A 20 year old male was admitted with history of inhaled tracheostomy tube. He had mild respiratory distress. He had undergone tracheostomy and insertion of Fuller's tube five years back to respiratory distress due to bilateral abductor paralysis of the vocal cords. He did not undergo lateralization of the vocal cords as planned by the surgeon and he was lost for followup. He was using the inner tube alone since 4 months following breakage of outer tube. Inner tube was broken at its neck and was inhaled 2 days prior to presentation. Following inhalation he had a bout of violent cough and he noticed the tube across the tracheostoma. X-ray neck was taken which showed inner tube across the stoma. (Fig.I). He was taken to the theatre where surgery was performed under local anaesthesia, the tube was slided down, since it was not

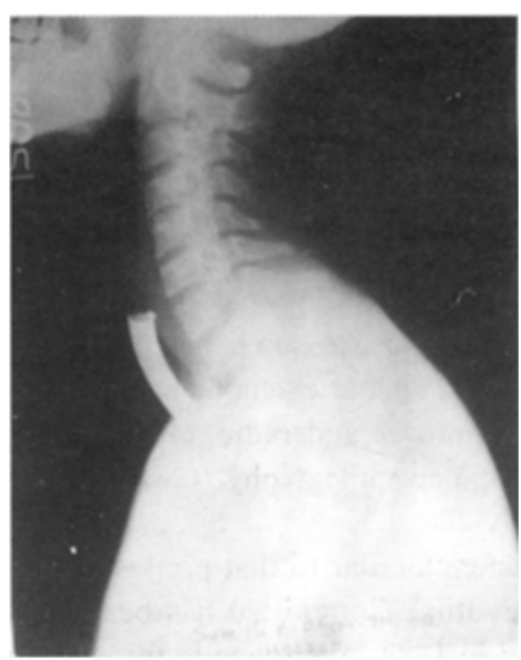

Fig. I : X-ray of neck showing tracheostomy tube

'Professor, ${ }^{2}$ Assistant Professor, ${ }^{3}$ Lecturer, ${ }^{4}$ Senior Resident, ${ }^{5}$ Senior Resident Department Of E.N.T. , Bapuji Hospital , J.J.M. Medical

College, Davangere - 577 004, Karnataka State, India.

Indian Journal of Otolaryngology and Head and Neck Surgery Vol. 55 No. 4, October - December 2003 


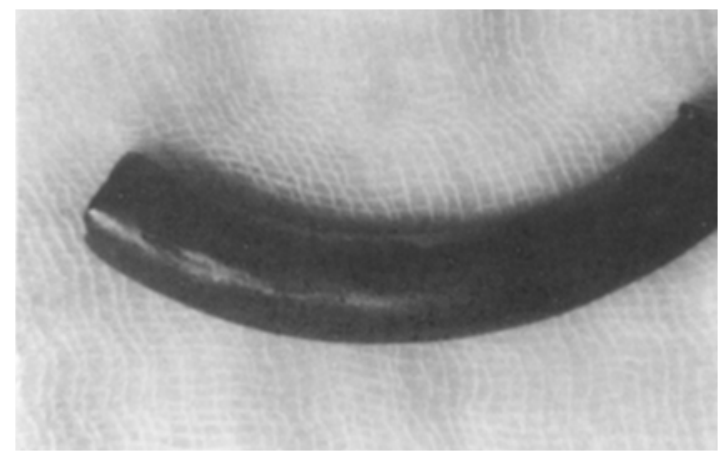

Fig. II : Showing removed tracheostomy tube

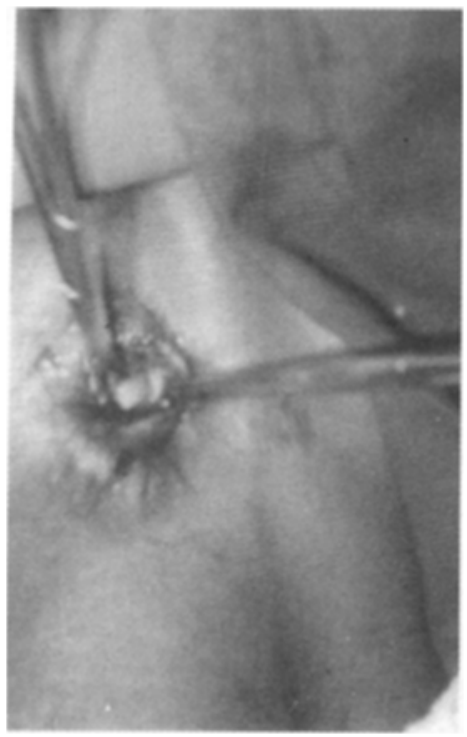

Fig. III : Showing removal of tracheostomy tube

possible to deliver the tube through the stoma a release incision was made at the upper border of the tracheostoma and tube was removed. (Fig.II) Jackson's tracheostomy tube was inserted and discharged with advise of regular followup.

\section{DISCUSSION}

Tracheostomy tube as a foreign body in tracheobronchial tree is one of the most rare problems. A number of factors predispose to the detachment of tracheostomy tube from the neck plate. Alkaline secretions and moisture from the tracheobronchial tree which stagnate over the tube can react with zinc and copper alloy which leads to the erosion of the metal described as 'season cracking'.,3,4. Fuller's tube is made from German Silver, the tube being braised to the neck plate with a substance, silver flow 55 . This contains zinc and copper, so erosion at this point may occur. Repeated removal, cleaning and boiling of the tube cause mechanical stress and early erosion ${ }^{5}$. If the fracture occurs within 14 days, it is considered as a defective manufacture of the material ${ }^{6}$. Most of the patients will not have serious problem unless the tube becomes blocked by secretions.

Usually the outer flanges of the tube are fractured and inhaled into the trachea or main bronchus: Very rarely inner tube becomes a foreign body in the tracheobronchial tree $^{2}$. This could be explained in our case by the reason that patient was using the inner tube alone for the maintenance of the airway on his own following breakage of outer tube. Usually it can be removed under local anaesthesia through the stoma. Sometimes a releasing incision is required as in our case ${ }^{5}$. (Fig.III) As per our knowledge no such case was reported in the literature, where the inner tube presented as a foreign body in the upper part of trachea across the tracheostoma.

The best way to minimise this complication is to properly train the patient in home tracheostomy care. They should be adequately stressed about the importance of regular follow-up where the surgeon would check for any signs of wear and tear of the tube.

\section{REFERENCES}

1. Foxen E.H.M. (1965) : In diseases of the ear, Nose and Throat, 2nd Edn., Vol.1, Edt. W.G. Scott Brown, J. Ballantyne and J. Groves, Butterworths, London ; 733pp.

2. Kakar P.K. and Saharia P.S. (1972) : "An unusual foreign body in the tracheo-bronchial tree". Journal of Laryngology and Otology ; 86: 1155-1157.

3. Bossoe H.H. and Boe J. (1960) : "Broken tracheostomy tube as a foreign body". Lancet; 1: 1006.

4. Maru Y.K., Puri N.D. and Majid A. (1978) : "An unusual foreign body in the tracheo-bronchial tree". Journal of Laryngology and Otology ; 92: 1045-8.

5) Bowlder D.A., Emery P.J. (1985) : "Tracheostomy tube fatigue : In unusual cause of inhaled foreign body". Journal* of Laryngology and Otology ; 99: 517-521.

6) Okafor B.C. (1983) : "Fracture of tracheostomy tubes : Pathogenesis and prevention". Journal of Laryngology and Otology ; 97: 771-774.

\section{Address for Correspondence :}

Dr. A.M. Shivakumar

E.N.T. Surgeon,

A.V. K. College Road, 2nd Main,

P.J. Extension, Davangere - 577004.

Karnataka, India. 